\title{
Genotyping of two Neisseria gonorrhoeae fluroquinolone-resistant strains in the Brazilian Amazon Region
}

\author{
William Antunes Ferreira ${ }^{1 /+}$, Cristina Motta Ferreira ${ }^{2}$, Felipe Gomes Naveca ${ }^{4}$, \\ Nayanne Cristina Oliveira da Silva Almeida ${ }^{3}$, Waldemara de Souza Vasconcelos ${ }^{1}$, \\ Jairo de Souza Gomes ${ }^{1}$, Maria de Fátima Pinto da Silva', Maria das Graças Costa Alecrim ${ }^{5}$ \\ ${ }^{1}$ Laboratório de Bacteriologia Clínica, Fundação Alfredo da Matta, Universidade Estadual do Amazonas, Rua Codajás 25, \\ 69065-130 Manaus, AM, Brasil ²Fundação de Hematologia e Hemoterapia do Amazonas, Manaus, AM, Brasil \\ ${ }^{3}$ Universidade Federal do Amazonas, Manaus, AM, Brasil ${ }^{4}$ Instituto Leônidas e Maria Deane-Fiocruz, Manaus, AM, Brasil \\ ${ }^{5}$ Fundação de Medicina Tropical Dr. Heitor Vieira Dourado, Manaus, AM, Brasil
}

We report two ciprofloxacin and ofloxacin-resistant Neisseria gonorrhoeae strains that were isolated from the urethral discharge of male patients at the sexually transmitted diseases outpatient clinic of the Alfredo da Matta Foundation (Manaus, state of Amazonas, Brazil). The gonococci displayed minimal inhibitory concentrations (> $32.00 \mu \mathrm{g} / \mathrm{mL}$ ) and three mutations in the quinolone resistance-determining region (S91F and D95G in GyrA and S87R in ParC). Both isolates were genotyped using N. gonorrhoeae multi-antigen sequence typing and the analysis showed that the ST225 which represented an emerging widespread multi-resistant clone that has also been associated with reduced susceptibility to ceftriaxone. We recommend continued surveillance of this pathogen to assess the efficacy of anti-gonococcal antibiotics in Brazil.

Key words: Neisseria gonorrhoeae - fluroquinolone resistance - gyrA and parC - genotyping - MAST

Two male patients, a 24-year-old and a 32-year-old, were treated at the sexually transmitted diseases (STD) clinic after presenting with urethral discharge and dysuria. The patients provided urethral culture swabs for Neisseria gonorrhoeae and were treated with a single oral dose of ciprofloxacin $(500 \mathrm{mg})$. Because the symptoms persisted, a single dose of ceftriaxone $(250 \mathrm{mg})$ intramuscular was administrated, which cured all of the symptoms. Tests later confirmed that both culture swabs were positive for N. gonorrhoeae. Both patients were human immunodeficiency virus-negative, although one of them was venereal disease research laboratory-reactive (1/4). One patient reported sexual contact with 10 casual partners in the last three months before infection, whereas the other patient reported two casual partners. It was not possible to know if patients had sexual contact in another state of Brazil or country.

The gonococci were screened using several tests, including beta-lactamase $\mathrm{BD} \mathrm{BBL}^{\mathrm{TM}}$ (BD, Franklin Lakes, NJ, USA), Serovar (Phadebact ${ }^{\circledR}$ GC Serovar Test, Bactus AB, Huddinge, Sweden) and E-test ${ }^{\circledR}$ (AB Biodisk, Solna, Sweden). The E-test ${ }^{\circledR}$ was performed using a media containing a GC Medium Base (BD-Difco ${ }^{\mathrm{TM}}$ ) and $1 \%$ defined growth supplements to ciprofloxacin, ofloxacin, chloramphenicol, ceftriaxone, azithromycin, penicillin and tetracycline. Reference values for sensitivity, reduced sensitivity or resistance were set according to the Clinical and Laboratory Standards Institute

\footnotetext{
+ Corresponding author:wianfe@yahoo.com.br

WAF, CMF and FGN contributed equally to this work.

Received 24 September 2010

Accepted 6 June 2011
}

(CLSI 2005a) and (Van Dick et al. 1999), specifically to chloramphenicol. The ATCC 49226 strain was used as a control for antibiotic quality.

The strains were not beta-lactamase producers and were classified in the WII-III serogroup with Bo, Bp, $\mathrm{Br}$, Bs and $\mathrm{Bt}$ serotypes. The isolates showed resistance to ciprofloxacin, ofloxacin ( $>32.00 \mu \mathrm{g} / \mathrm{mL}$ ) and chloramphenicol $(3 \mu \mathrm{g} / \mathrm{mL}$ and $2 \mu \mathrm{g} / \mathrm{mL})$. One strain was classified as having chromosomally-mediated resistance to penicillin [non-PPNG, non-TRNG with penicillin, minimal inhibitory concentrations (MIC) of $\geq 2 \mu \mathrm{g} / \mathrm{mL}$ and tetracycline MIC of $\leq 2 \mu \mathrm{g} / \mathrm{mL}]$ and reduced susceptibility to tetracycline $(0.75 \mu \mathrm{g} / \mathrm{mL}$ and $0.500 \mu \mathrm{g} / \mathrm{mL})$. Both strains were susceptible to azithromycin $(0.125 \mu \mathrm{g} /$ $\mathrm{mL}$ and $0.190 \mu \mathrm{g} / \mathrm{mL}$ ). MIC values were $0.064 \mu \mathrm{g} / \mathrm{mL}$ and $0.032 \mu \mathrm{g} / \mathrm{mL}$. The agar dilution method was used to confirm MICs of ciprofloxacin and ofloxacin at $>32.00$ $\mu \mathrm{g} / \mathrm{mL}$. The major difference (phenotypic or genotypic) between the two strains was related to the level of penicillin resistance (Table).

Fragments of $\operatorname{gyr} A$ (278 bp) and $\operatorname{parC}(254 \mathrm{bp})$ genes, which corresponded to the quinolone resistance-determining region (Belland 1994), were polymerase chain reaction (PCR)-amplified and sequenced in both directions using the BigDye Terminator Cycle Sequence kit 3.1 in an ABI 3130 genetic analyzer (Applied Biosystems). Residue substitutions were identified by comparing the predicted amino acid sequences of the isolates from this study with the wild-type GyrA and ParC sequences (Genbank accessions: AAA82128 and AAA82151, respectively). The sequencing analysis identified mutations in residues 91 and 95 (Ser91Phe and Asp95Gly) of GyrA and Ser87Arg of ParC, which have already been associated with the fluroquinolone resistance phenotype (Belland et al. 1994, Tiejun et al. 2009). 
TABLE

Genotypic and phenotypic characterization of fluoroquinolone-resistant Neisseria gonorrhoeae in Manaus, state of Amazonas, Brazil

\begin{tabular}{|c|c|c|}
\hline \multirow[b]{2}{*}{ Characteristics } & \multicolumn{2}{|c|}{ N. gonorrhoeae strains } \\
\hline & FUAM84 & FUAM103 \\
\hline Collection date & 4 May 2009 & 7 July 2009 \\
\hline$\beta$-lactamase & Negative & Negative \\
\hline Serovar & WII, WIII & WII, WIII \\
\hline Serotype & $\mathrm{Bo}, \mathrm{Bp}, \mathrm{Br}, \mathrm{Bs}, \mathrm{Bt}$ & $\mathrm{Bo}, \mathrm{Bp}, \mathrm{Br}, \mathrm{Bs}, \mathrm{Bt}$ \\
\hline Azithromycin & Sensitive $(0.125 \mu \mathrm{g} / \mathrm{mL})$ & Sensitive $(0.190 \mu \mathrm{g} / \mathrm{mL})$ \\
\hline Ceftriaxone & Reduced susceptibility $(0.064 \mu \mathrm{g} / \mathrm{mL})$ & Sensitive $(0.032 \mu \mathrm{g} / \mathrm{mL})$ \\
\hline Ciprofloxacin & Resistant $(>32.00 \mu \mathrm{g} / \mathrm{mL})$ & Resistant $(>32.00 \mu \mathrm{g} / \mathrm{mL})$ \\
\hline Chloramphenicol & Resistant $(3.000 \mu \mathrm{g} / \mathrm{mL})$ & Resistant $(2.000 \mu \mathrm{g} / \mathrm{mL})$ \\
\hline Ofloxacin & Resistant $(>32.00 \mu \mathrm{g} / \mathrm{mL})$ & Resistant $(>32.00 \mu \mathrm{g} / \mathrm{mL})$ \\
\hline Penicillin & Reduced susceptibility $(0.750 \mu \mathrm{g} / \mathrm{mL})$ & Resistant $(2.000 \mu \mathrm{g} / \mathrm{mL})$ \\
\hline Tetracycline & Reduced susceptibility $(0.500 \mu \mathrm{g} / \mathrm{mL})$ & Reduced susceptibility $(0.750 \mu \mathrm{g} / \mathrm{mL})$ \\
\hline $\mathrm{QRDR}^{a}$ & (GyrA - S91F, D95G), (ParC - S87R) & (GyrA - S91F, D95G), (ParC - S87R) \\
\hline Genotype (NG-MAST) & ST225 & ST225 \\
\hline
\end{tabular}

a: quinolone resistance-determining region; NG-MAST: $N$. gonorrhoeae multi-antigen sequence typing.

To further characterise the isolates of this study, $N$. gonorrhoeae multi-antigen sequence typing (NGMAST) was performed as described earlier by Martin et al. (2004). Briefly, internal fragments of the por (737 bp) and $t b p B(553 \mathrm{bp})$ genes were PCR-amplified and sequenced in both directions as described for $g y r A$ and parC genes. Nucleotide sequences were revised, trimmed and submitted to the public NG-MAST website from ng-mast.net/ for por and $t b p B$ typing and ST assignment. All nucleotide sequences that were identified in this study are available in the GenBank database under the following accessions: JF693604, JF693605, JF693606, JF693607, JF693608, JF693609, JF693610 and JF693611.

In 2009, 2,759 cases of STDs (diagnosed etiologically) and 903 cases of vaginal, cervical or urethral discharge (diagnosed syndromically) were reported at our facility, which is a public hospital in Manaus, the capital of the state of Amazonas, Brazil. In this hospital, gonococcal infections are the third most reported disease, with 241 cases registered in 2009 and annual media of 518 over the past 12 years (1997-2009) (Management of Epidemiology 2010)

Since 1999, susceptibility tests that have been conducted at the Alfredo da Matta Foundation have shown an increasing resistance of gonococci to antibiotics, including $5.5 \%$ reduced susceptibility to ciprofloxacin, $6.4 \%$ of resistance to azithromycin, $21 \%$ of resistance to penicillin and $80 \%$ of resistance to tetracycline (Ferreira et al. 2007).

Both fluoroquinolone-resistant gonococci that were sampled in this study had mutations that are associated with MIC $>32.00 \mu \mathrm{g} / \mathrm{mL}$. Similar levels of resistance have been reported in several countries worldwide (Pauillac et al. 2009, Tiejun et al. 2009), particularly in Southeast
Asia (WHO 2002, Ilina et al. 2008, Starnino \& Stefanelli 2009), and represent a serious therapeutic challenge.

The NG-MAST single locus sequence query for por and $t b p B$ showed the same results for the two isolates, which were typed as por allele number 4 and $t b p B$ allele number 4. Based on this two-locus-combined profile, the isolates were equally assigned as ST225, which indicates a shared ancestral origin for these isolates. The ST225 seems to be an emerging multi-resistant clone that has been recently identified in many countries such as Australia (Todd et al. 2007), Scotland (Palmer et al. 2008), France (Monfort et al. 2009), Portugal (Florindo et al. 2010) and Greece (Mavroidi et al. 2011). In fact, ST225 was the most prevalent ST in Scotland and France and has been reported as the second major genotype among QRNG isolates that were collected between 1997-2007 in Greece.

The detection of the ST225 clone in Brazil must be considered with special attention because it has been associated with resistance to tetracycline and ciprofloxacin. In addition, ST225 was recently associated with reduced susceptibility to ceftriaxone (Monfort et al. 2009, Whiley et al 2010). Until now, the CLSI (2010b) did not stipulate MIC values to reduced susceptibility or resistance to ceftriaxone. In accordance with these data, the isolate FUAM84 (MIC: $0.064 \mu \mathrm{g} / \mathrm{mL}$ ) shall be considered a possible clone with reduced ceftriaxone susceptibility.

Due to the high levels of resistance to traditional antibiotics, cephalosporins has often been used as a firstline medication to treat uncomplicated and disseminated gonococcal infections (GISP 2009, Rosen et al. 2009). In cases of therapeutic failure during treatment of gonococcal infections with fluroquinolones in Brazil, ceftriaxone is recommended as a first therapeutic choice followed by cefixime or spectinomycin as a second choice (MS 2006). 
To our knowledge, there have been no previous reports about the genotyping of $N$. gonorrhoeae and molecular characterisation of gyrA and parC-resistant mutations in Brazil. However, decreased susceptibility (Ferreira et al. 2007) and resistance (Belda et al. 2007) to ciprofloxacin have been reported in Manaus and São Paulo.

Those findings represent an important epidemiological situation in the region and should be used to determine an appropriate method to treat gonococcal infections in Manaus. The inadequate and indiscriminate use of antibiotics may have contributed to the emergence of these antibiotic-resistant strains, which diminishes the efficacy of anti-gonococcal infection therapies. We recommend close surveillance of this pathogen in Manaus and in other Brazilian cities to evaluate whether its response to the first-line recommended antibiotic treatment changes over time.

\section{ACKNOWLEDGEMENTS}

To Brazilian Ministry of Health, to George Allan Villarouco da Silva (biologist), Cíntia Mara Costa de Oliveira (biologist), José Carlos Baranda (pharmacist), José Carlos Gomes Sardinha (MD) and Maísa Porto dos Santos (biologist), to the professionals of the STI outpatient clinic and to the Superintendence of the Manaus Free-Trade Zone.

\section{REFERENCES}

Belda JW, Velho PENF, Arnone M, Fagundes LJ 2007. Emergence of fluoroquinolone-resistant Neisseria gonorrhoeae in São Paulo, Brazil. Braz J Microbiol 38: 293-295.

Belland RJ, Morrison SG, Ison C, Huang WM 1994. Neisseria gonorrhoeae acquires mutations in analogous regions of gyrA and parC in fluoroquinolone-resistant isolates. Mol Microbiol 14: 371-380.

CLSI - Clinical Laboratory Standard Institute 2005a. Performace standards for antimicrobial susceptibility testing, 15th Information Suplement M100-S15, CLSI, Wayne, 177 pp.

CLSI - Clinical and Laboratory Standards Institute 2010b. Performance standards for antimicrobial susceptibility testing, 20th Information Suplement M100-S20, CLSI, Wayne, 156 pp.

Ferreira WA, Vasconcelos WS, Silva MFP, Gomes JS, Ferreira CM, Benzaken AS, Silva MIS 2007. Resistance of Neisseria gonorrhoeae to antibiotics in Manaus. Period 2005-2006. J bras Doenças Sex Transm 19: 65-69.

Florindo C, Pereira R, Boura M, Nunes B, Paulino A, Gomes JP, Borrego MJ 2010. Genotypes and antimicrobial-resistant phenotypes of Neisseria gonorrhoeae in Portugal (2004-2009). Sex Transm Infect 86: 449-453.

GIPS - Gonococcal Isolate Surveillance Project 2009. Sexually transmitted disease surveillance 2007, Annual report 2007, Supplement 2009, Division of STD Prevention, Atlanta, 24 pp.

Ilina EN, Vereshchagin VA, Borovskaya AD, Malakhova MV, Sidorenko SV, Al-Khafaji NC, Kubanova AA, Govorun VM 2008.
Relation between genetic markers of drug resistance and susceptibility profile of clinical Neisseria gonorrhoeae strains. Antimicrob Agents Chemother 52: 2175-2182.

Management of Epidemiology and Diseases Control 2010. Foundation of Tropical Dermatology and Venereology Alfredo da Matta. Available from: fuam.gov.br.

Martin IMC, Ison CA, Aanensen DM, Fenton KA, Spratt BG 2004. Rapid sequence-based identification of gonococcal transmission clusters in a large metropolitan area. J Infect Dis 189: 1497-1505.

Mavroidi A, Tzelepi E, Siatravani E, Godoy D, Miriagou V, Spratt BG 2011. Analyzing the emergence of quinolone-resistant gonococci in Greece by the combined use of Neisseria gonorrhoeae multiantigen sequence typing and multi-locus sequence typing. $J$ Clin Microbiol 49: 1196-1201.

Monfort L, Caro V, Devaux Z, Delannoy AS, Sylvain B, Patrice S 2009. First Neisseria gonorrhoeae Genotyping Analysis in France: identification of a strain cluster with reduced susceptibility to ceftriaxone. J Clin Microbiol 47: 3540-3545.

MS - Ministério da Saúde 2006. Manual de controle das doenças sexualmente transmissiveis/DST, 4th ed., Secretaria de Vigilância em Saúde/Programa Nacional de DST e AIDS, Brasília, 148 pp.

Palmer HM, Young H, Winter A, Dave J 2008. Emergence and spread of azithromycin-resistant Neisseria gonorrhoeae in Scotland. J Antimicrob Chemother 62: 490-494.

Pauillac FV, Hogan TR, Tapsall JW, Goarant C 2009. Quinolone-resistance in Neisseria gonorrhoeae: rapid genotyping of QRDRs in gyrA and parC genes by melting curve analysis predicts susceptibility. Antimicrob Agents Chemother 53: 1264-1267.

Rosen T, Vandergriff T, Harting M 2009. Antibiotic use in sexually transmissible diseases. Dermatol Clin 27: 49-61.

Starnino S, Stefanelli P 2009. On behalf of the Neisseria gonorrhoeae Italian Study Group. J Antimicrob Chemother 63: 1200-1204.

Tiejun Z, Xiaoming Z, Jilun Z, Yinghu Z, Yanhua R, Yue C, Weiming G, Tao Z, Qingwu J 2009. Fluoroquinolone resistance among Neisseria gonorrhoeae isolates from Shanghai, China: detection of quinolone resistance determining region mutations. Indian $J$ Med Res 129: 701-706.

Todd K, Durrheim D, Pickles R, Eastwood K, Merritt T, Tapsall J, Ray S, Limnios A 2007. Using epidemiological and molecular methods to investigate an outbreak of gonorrhoea associated with heterosexual contact in Newcastle, NSW, Australia. Sex Health 4: 233-236.

Van Dick E, Meheus AZ, Piot P 1999. Laboratory diagnosis of sexually transmitted diseases, WHO, Geneva, $135 \mathrm{pp}$.

Whiley DM, Goire N, Lambert SB, Ray S, Limnios EA, Nissen MD, Sloots TP, Tapsall JW 2010. Reduced susceptibility to ceftriaxone in Neisseria gonorrhoeae is associated with mutations G542S, P551S and P551L in the gonococcal penicillin-binding protein 2. $J$ Antimicrob Chemother 65: 1615-1618.

WHO - Word Health Organization Western Pacific Gonococcal Antimicrobial Surveillance Programme 2002. Surveillance of antibiotic resistance in Neisseria gonorrhoeae in the WHO Western Pacific region, 2002. Commun Dis Intell 27: 488-491. 